\title{
Morphology and thermal stability of silk fibroin/ starch blended microparticles
}

\author{
Y. Baimark*, M. Srisa-ard, P. Srihanam \\ Department of Chemistry and Center of Excellence for Innovation in Chemistry, Faculty of Science, Mahasarakham \\ University, Mahasarakham 44150, Thailand
}

Received 24 May 2010; accepted in revised form 25 August 2010

\begin{abstract}
In the present study biodegradable microparticles of silk fibroin (SF)/starch blends were prepared by a simple water-in-oil emulsion solvent diffusion technique. SF/starch blended solution and ethyl acetate were used as water and oil phases, respectively. The influence of SF/starch ratios on characteristics of the blended microparticles was investigated. The SF conformation of microparticle matrices from FTIR analysis was changed from random coil to $\beta$-sheet form by blending with starch. The blended microparticles had lower dissolution in water than those of SF and starch microparticles. The 1/3 (w/w) SF/starch blended microparticles exhibited the lowest dissolution. The SF and starch microparticles showed irregular and deflated shapes, respectively. The blended microparticles were nearly spherical in shapes and smaller sizes. Thermal stability of the blended microparticles slightly increased with the starch blended ratio. The results suggested that SF conformational transition, thermal stability, morphology and dissolution of the blended microparticles can be adjusted by varying the blended ratio.
\end{abstract}

Keywords: biopolymers, silk fibroin, starch, conformational transition, morphology

\section{Introduction}

Silk fibroin (SF) is a biodegradable and biocompatible natural protein polymer created by the Bombyx mori silkworm $[1,2]$ and has recently been extensively investigated as a biomaterial suitable for uses such as a matrix for cell culture substrates [3] and drug delivery systems $[4,5]$. The minimal inflammatory reactions in vitro and in vivo of SF have been reported [6]. The SF has been processed into fibers, films and particles. Most research work has been focused on the widely studied SF films. However, the applications of SF films are limited due to their being very brittle in the dry state. The poor mechanical properties of the SF film could be improved by blending it with other polymers $[7,8$, 9]. Other properties, such as conformational transition and thermal properties are dependant on the blended ratios. Preparation of SF microparticles by various techniques has been reported for drug delivery applications $[4,5,10-13]$. The SF/chitosan blended microparticles have been prepared by the coacervation/cross-linking method [14]. Starch is a non-toxic, biodegradable, biocompatible, edible and relative inexpensive material that has been widely studied in the entrapment of food ingredients $[15,16]$ and drugs [17-19]. Almost all starch microparticles have been prepared by an emulsification-cross-linking reaction [17-20]. The preparation of alginate/starch blended microparticles has been reported by Roy et al. [21]. However, no information on $\mathrm{SF} /$ starch blended microparticles has been published.

In the present work, we report the conformational transition, morphology and thermal stability of 
$\mathrm{SF} / \mathrm{starch}$ blended microparticles as a function of blended ratios. The dissolution in water of $\mathrm{SF} /$ starch blended microparticles was also determined.

\section{Materials and methods}

\subsection{Materials}

Silk cocoons from B. mori were kindly supplied by the Silk Innovation Center, Mahasarakham University, Mahasarakham, Thailand. $\mathrm{Na}_{2} \mathrm{CO}_{3}(99.5 \%$, Carlo Erba, code no. 479306, MI, USA), $\mathrm{CaCl}_{2}$ (94\%, Unilab, code no. 0701013, Auckland, New Zealand), ethanol (99.8\%, Carlo Erba, code no. 414608, France) and ethyl acetate (99.8\%, Lab Scan, code no. A3511, Ireland) were used without further purification. Cassava starch (food grade, 96\% starch, amylase content $16.8 \%$ ) was purchased from Bangkok Inter Food Co., Ltd. (Bangkok, Thailand) and used without pretreatment.

Aqueous silk fibroin (SF) solution was prepared as follows. Silk cocoons were de-gummed by boiling in $0.5 \% \mathrm{Na}_{2} \mathrm{CO}_{3}$ solution at $95^{\circ} \mathrm{C}$ for $30 \mathrm{~min}$ to remove sericin and then rinsed with distilled water before drying at room temperature. De-gummed SF fibers were dissolved in the ternary solvent system, $\mathrm{CaCl}_{2}$-ethanol-water (mole ratio $=1: 2: 8$ ), by stirring at $90^{\circ} \mathrm{C}$. The SF solution was then dialyzed in cellulose tubular membranes (molecular weight cut-off 7000 Da, Lot\# KC132124, Thermo Scientific, IL, USA) against distilled water for 3 days. After filtration, the SF concentration was adjusted to $1 \% \mathrm{w} / \mathrm{v}$ with distilled water. The $1 \% \mathrm{w} / \mathrm{v}$ starch solution was prepared by dispersing starch in distilled water at $80^{\circ} \mathrm{C}$ and stirring until gelatinization.

\subsection{Preparation of blended microparticles}

$\mathrm{SF} /$ starch blended solutions were firstly prepared by mixing SF and starch solutions with a magnetic stirrer for $1 \mathrm{hr}$ before microparticle formation. The blended microparticles were fabricated in a onestep process by the water-in-oil (W/O) emulsion solvent diffusion method. Briefly, about $1.0 \mathrm{ml}$ of blended solution was slowly added drop-wise into $200 \mathrm{ml}$ of ethyl acetate with magnetic stirring at $900 \mathrm{rpm}$ for $1 \mathrm{hr}$. The beaker was closed with aluminum foil to prevent organic solvent evaporation during the emulsification-diffusion process. The blended microparticles were recovered by centrifugation before being dried in a vacuum oven at room temperature overnight to remove residue organic solvent. Microparticles with $\mathrm{SF} / \mathrm{starch}$ blended ratios of $4 / 0,3 / 1,2 / 2,1 / 3$ and $0 / 4(w / w)$ were prepared and investigated.

\subsection{Characterization of blended microparticles}

The chemical structures and conformational transition of the microparticles were measured with Fourier transform infrared (FTIR) spectroscopy using a Spectrum GX FTIR spectrophotometer (Perkin-Elmer Co. Ltd., Massachusetts, USA) with air as the reference. The resolution of $4 \mathrm{~cm}^{-1}$ and 32 scans were used. FTIR spectra were obtained using a $\mathrm{KBr}$ disk method. Thermal stability of the microparticles was analyzed by thermogravimetry (TG) using a SDT Q600 thermogravimetric analyzer (TA-Instrument Co. Ltd., New Castle, DE, USA). For TG analysis, 5-10 mg sample was heated from 50 to $1000^{\circ} \mathrm{C}$ at a heating rate of $20^{\circ} \mathrm{C} / \mathrm{min}$ under a nitrogen atmosphere. Morphologies of the microparticles were determined by scanning electron microscopy (SEM) using a JSM-6460LV SEM (JEOL, Tokyo, Japan). The microparticles were coated with gold to enhance the surface conductivity before scanning. Particle size distribution of the microparticles was measured by the sieving method. For this purpose, the microparticles were sieved into three particle size ranges of $<80,80-150$ and $>150 \mu \mathrm{m}$ before weighing. A dissolution test of microparticles in distilled water was performed. For this test, the microparticles were incubated in $20 \mathrm{ml}$ of distilled water at $30^{\circ} \mathrm{C}$ and shaken at $100 \mathrm{rpm}$. The incubation times of 3 and $6 \mathrm{hrs}$ were used. At the appropriate time, residual microparticles were separated by centrifugation at $10000 \mathrm{rpm}$ for $20 \mathrm{~min}$ before drying at $50^{\circ} \mathrm{C}$ in a vacuum oven for $24 \mathrm{hrs}$. The remaining SF microspheres were weighted after being stored in a desiccator for $6 \mathrm{hrs}$. Percentage of dissolution was calculated from Equation (1). The mean \% dissolution values are the average of three parallel measurements. The differences between data sets are expressed by analysis of variance (ANOVA) and multiple $t$ tests. $\leq 0.05$ was considered the statistically significant. 
$\%$ dissolution $=\frac{\text { initial microparticles }[\mathrm{mg}]-\text { remaining microparticles }[\mathrm{mg}]}{\text { initial microparticles }[\mathrm{mg}]} \cdot 100$

where initial and remaining microparticles are the weights of microparticles before and after dissolution tests, respectively.

\section{Results and discussion}

\subsection{FT-IR analysis}

The functional groups of SF and starch components, and SF conformational transition were determined from the FTIR spectra of pure and blended microparticles as shown in Figure 1. The positions of absorption bands, especially amide I, II and III bands indicate the conformational transition of SF. The FTIR spectrum of SF microparticles (Figure 1a) showed absorption bands at $1654 \mathrm{~cm}^{-1}$ (amide I), $1545 \mathrm{~cm}^{-1}$ (amide II) and $1240 \mathrm{~cm}^{-1}$ (amide III), assigned to the random coil SF conformation. The FTIR results indicated that the SF microparticle matrices were predominantly in random coil form. Whereas FTIR spectrum of starch microparticles in Figure 1e showed broad absorption bands at $3385-3550$ and $2929 \mathrm{~cm}^{-1}$ due to $\mathrm{O}-\mathrm{H}$ and $\mathrm{C}-\mathrm{H}$ stretching. The band at $1415 \mathrm{~cm}^{-1}$ is assigned to $\mathrm{C}-\mathrm{H}$ bending vibration. While the absorption band at $1000-1155 \mathrm{~cm}^{-1}$ can be attributed to the saccharide structure of starch $[20,21]$. As would be expected, band characteristics of both SF and starch were detected in the FTIR spectra of the blended microparticles. Intensities of starch characteristic bands at 2929, 1415 and 1000$1155 \mathrm{~cm}^{-1}$ increased with the starch blended ratio (Figures 1b-1d). It should be noted that the FTIR spectra of $2 / 2$ and $1 / 3 \mathrm{SF} /$ starch blended micropar-

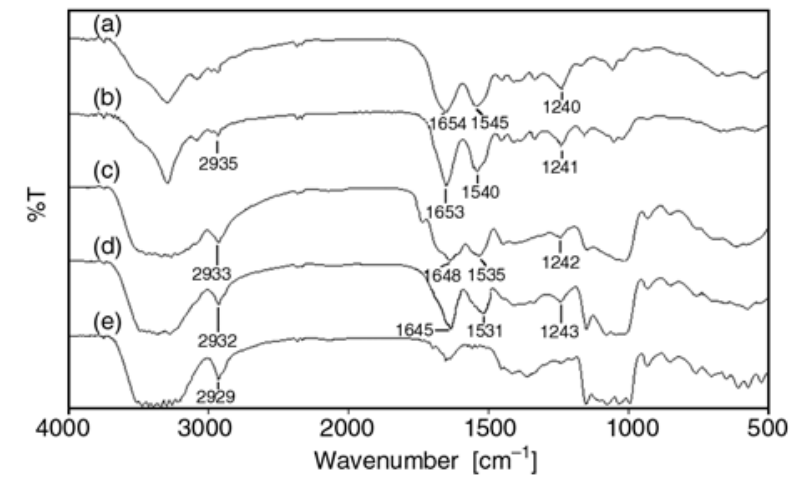

Figure 1. FTIR spectra of (a) SF, (b) 3/1 blended, (c) 2/2 blended, (d) 1/3 blended and (e) starch microparticles ticles showed $\mathrm{O}-\mathrm{H}$ stretching bands of starch in the range of $3385-3550 \mathrm{~cm}^{-1}$. While the FTIR spectrum of $3 / 1 \mathrm{SF} /$ starch blended microparticles exhibited $\mathrm{N}-\mathrm{H}$ stretching bands of $\mathrm{SF}$ at $3400 \mathrm{~cm}^{-1}$.

It can be seen that the amide I and II bands of SF shifted slightly to a lower wave number after blending with starch. This shifting increased as the starch in the blended ratio increased. Whereas the amide III bands of SF shifted to a higher wave number after blending with starch. The results indicated that the SF microsphere matrices changed from random coil to $\beta$-sheet form. The fraction of $\beta$-sheet SF form of the blended microparticles increased as the starch blended ratio increased, suggesting interaction and miscibility between SF and starch. The shifting of SF amide bands in the FTIR spectra of its blends has been used to detect interactions and miscibility between SF and blended molecules $[8$, $22,23]$. For SF/hydroxyl propyl methyl cellulose (HPMC) blends, it has been proposed that the hydrogen bonding between $\mathrm{NH}$ in the amide groups of SF and OH of HPMC had occurred [22]. Therefore, the intermolecular bonds in the SF/starch blends in this work may be expected to be hydrogen bonding between $\mathrm{NH}$ in the amide groups of $\mathrm{SF}$ and $\mathrm{OH}$ of starch.

\subsection{Morphology}

The microparticles were formed and solidified after diffusion out of water from dispersed emulsion droplets to the continuous ethyl acetate phase. The microparticles suspended in ethyl acetate were obtained before being collecting by centrifugation. Morphology of the microparticles was characterized from the SEM images, as shown in Figure 2. It was found that the SF microparticles had an irregular-shape (Figure 2a). The microparticles of other proteins such as insulin have been prepared by the spray-drying method [24]. They were erythrocytelike in shape. Solid shells formed because the drying started at the outside of the droplets. Almost all starch microparticles showed deflated-like shapes (Figure 2e). So, it was surprising that the blended microparticles were nearly spherical in shape and had a smooth surface (Figures 2b-2d). It should be 


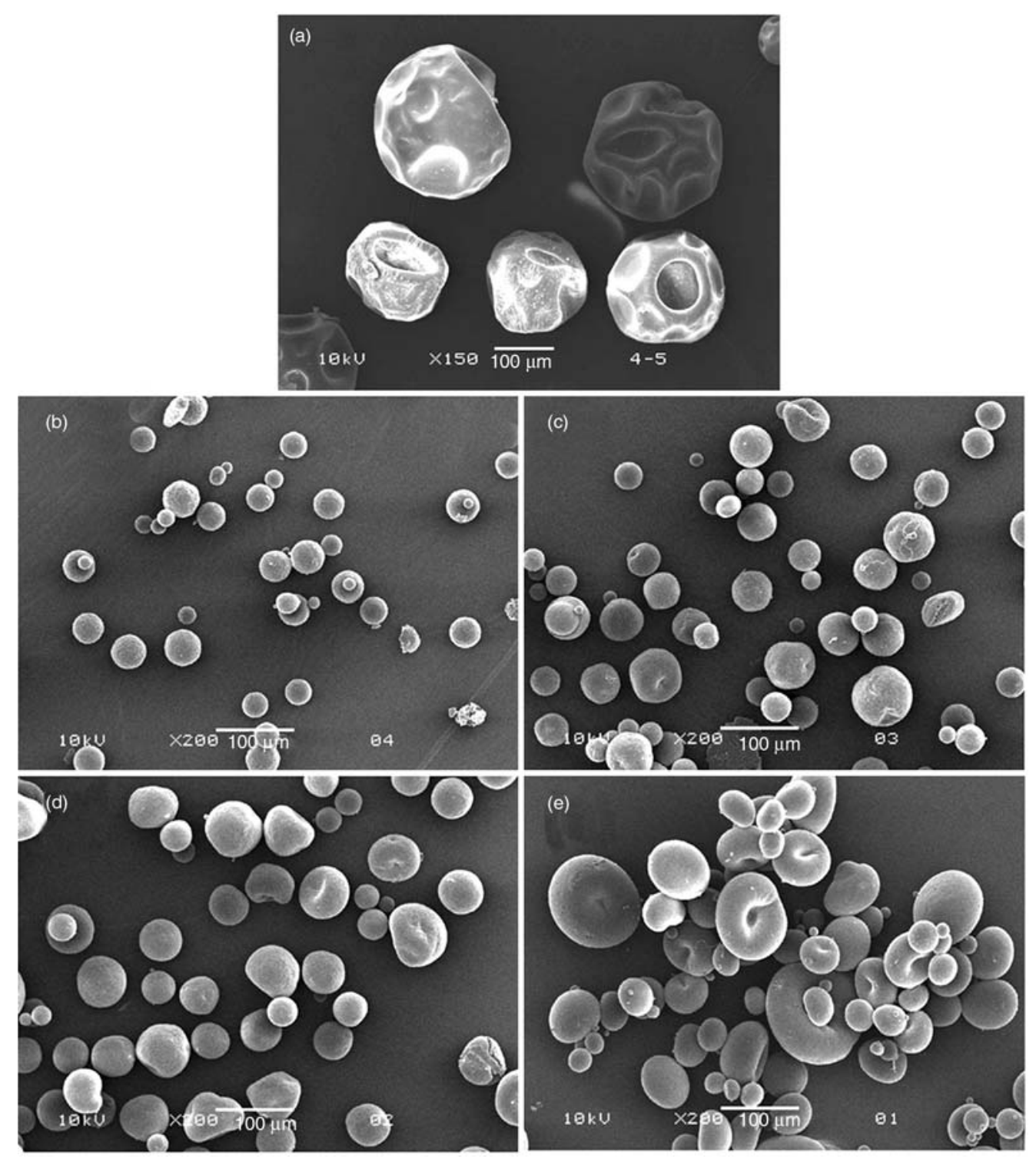

Figure 2. SEM micrographs of (a) SF, (b) 3/1 blended, (c) 2/2 blended, (d) 1/3 blended and (e) starch microparticles. All bars $=100 \mu \mathrm{m}$.

noted that the blended microparticles with SF/ starch blended ratio of $3 / 1(\mathrm{w} / \mathrm{w})$ exhibited a uniform spherical shape compared to the other blended ratios. Some deflated microparticles can be found when the starch blended ratio was increased. This suggests that in the blending of SF with starch at appropriate ratios, uniformly spherical-shaped microparticles with smooth surfaces could be fabricated by the W/O emulsion solvent diffusion method.

The internal morphology of microparticles was determined from the SEM images of broken surfaces, as illustrated in Figure 3. This indicates that the microparticles contained voids or porous structures. The starch microparticle matrix was denser than that of the SF microparticle matrix. The numbers of voids decreased as the starch in the blended ratio increased. However, these porous forms were completely covered with a smooth surface for all blended ratios. Porous microparticles of a waterinsoluble polymer have been prepared by the water ${ }_{1}$-in-oil-in-water $2\left(\mathrm{~W}_{1} / \mathrm{O} / \mathrm{W}_{2}\right)$ double emulsion method $[25,26]$. The void structures were formed and solidified because of the diffusion out of $\mathrm{W}_{1}$ to $\mathrm{W}_{2}$ phase. It would be expected that the porous structures of SF, starch and their blended microparticles occurred due to diffusion out of water from emulsion droplets to the external ethyl acetate phase. 

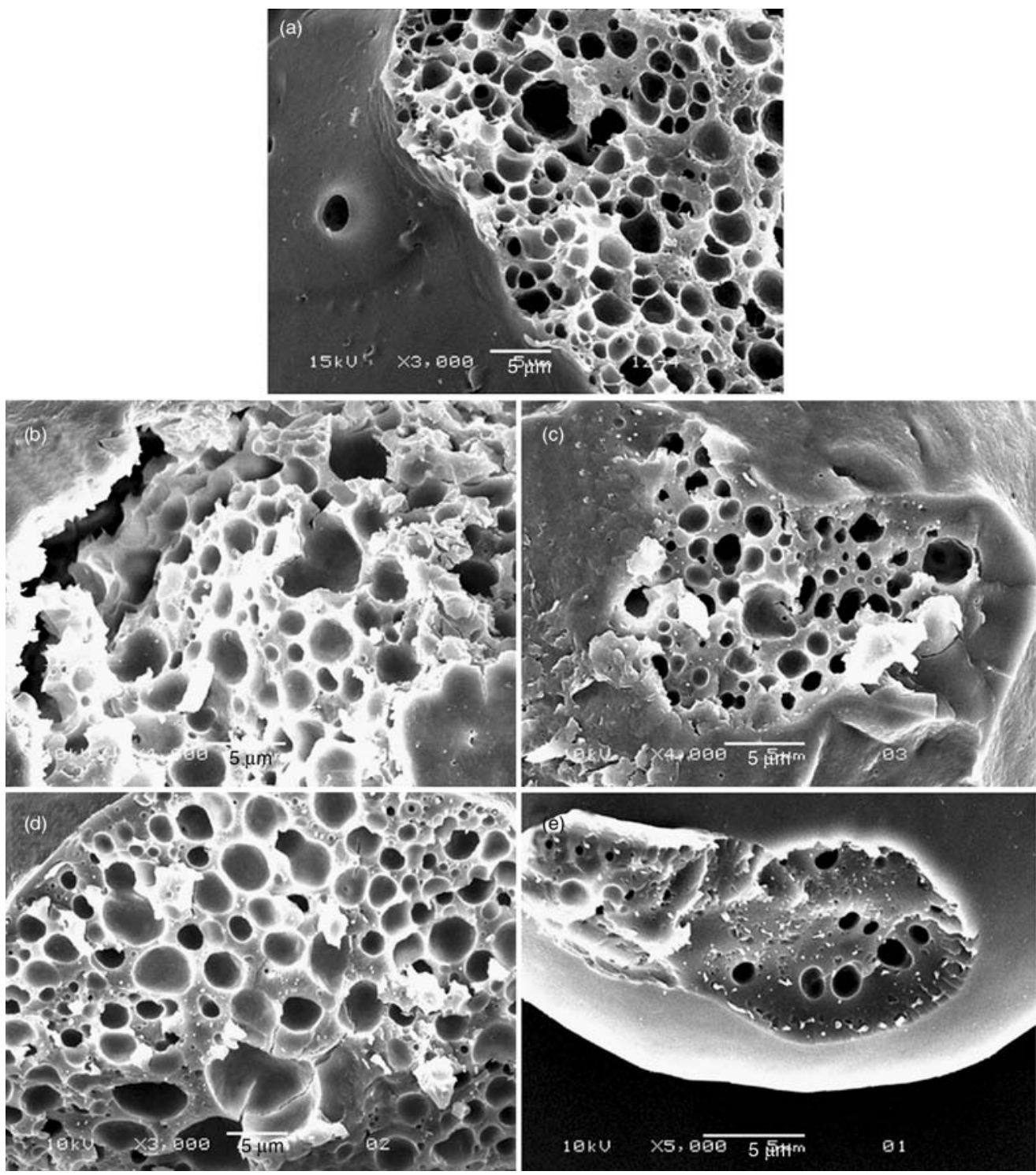

Figure 3. SEM micrographs of broken surfaces of (a) SF, (b) 3/1 blended, (c) 2/2 blended, (d) 1/3 blended and (e) starch microparticles. All bars $=5 \mu \mathrm{m}$.

\subsection{Thermal stability}

Decomposition and thermal stability of SF, starch and blended microparticles was determined from thermogravimetric (TG) thermograms as shown in Figure 4. Both the SF and starch micropaticles did not completely decompose at a temperature of $1000^{\circ} \mathrm{C}$. The TG thermograms of SF, starch and blended microparticles showed a single decomposition stage. The remaining weights at $1000^{\circ} \mathrm{C}$ were approximate 30 and $8 \%$ for SF and starch microparticles, respectively. The remaining weights at $1000^{\circ} \mathrm{C}$ of all blended microparticles were similar to the SF microparticles. The remaining weights at $1000^{\circ} \mathrm{C}$ of blended microparticles slightly decreased as the $\mathrm{SF}$ in the blended ratio decreased (Figures $4 b-4 d)$.

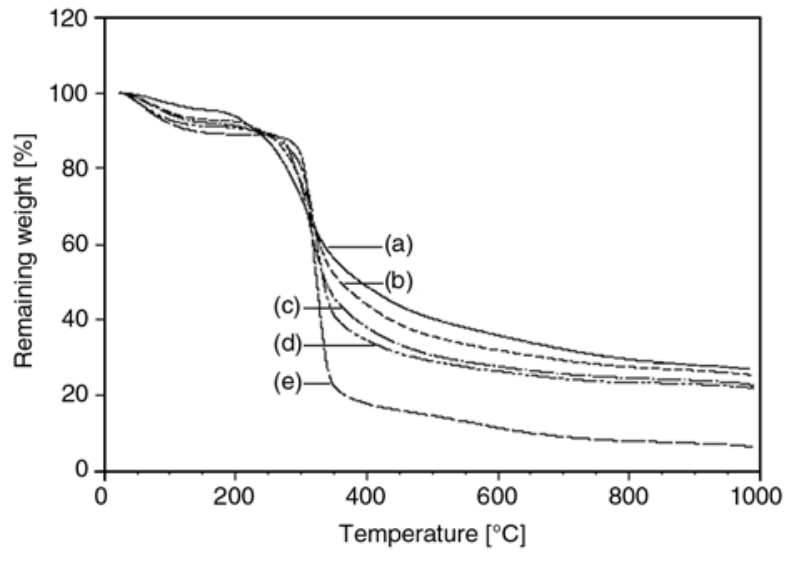

Figure 4. TG thermograms of (a) SF, (b) 3/1 blended, (c) $2 / 2$ blended, (d) $1 / 3$ blended and (e) starch microparticles

For SF microparticles (Figure 4a), it can be seen that they exhibited two major weight loss phases. 
The initial weight loss at around $100^{\circ} \mathrm{C}$ is due to loss of moisture. The weight loss in this phase depends on the moisture content of the SF microparticles. The sharp weight loss in the second phase took place in the temperature range of $200-400^{\circ} \mathrm{C}$ associated with the breakdown of side chain groups of amino acid residues as well as the cleavage of peptide bonds. For starch microparticles (Figure $4 \mathrm{e}$ ), the first phase shows the evaporation/dehydration that begins immediately after the temperature is increased and finishes at around $100^{\circ} \mathrm{C}$. The moisture content of starch microparticles was higher than that of the SF microparticles. The thermal decomposition in the second phase of starch microparticles started at approximately $300^{\circ} \mathrm{C}$. The TG thermograms of blended microparticles also present two phases of weight losses. The initial weight losses occurred due to moisture content exhibit between SF and starch microparticles. However, the second weight loss phase of blended microparticles did not separate.

The thermal stability of the samples can be clearly observed from differential TG (DTG) thermograms as shown in Figure 5. The small peaks in the range of $50-150^{\circ} \mathrm{C}$ occurred from moisture evaporation. The large peaks in the range of $150-500^{\circ} \mathrm{C}$ were due to decomposition of SF and starch microparticle matrices. From DTG thermograms, the temperature of maximum decomposition rate $\left(T_{d, \max }\right)$ can be determined and has been summarized in Table 1. The blended microparticles had a single $T_{d, \text { max }}$ between the SF and starch components. The $T_{d, \max }$ values of the blended microparticles slightly increased as the starch in the blended ratio increased. This supports the intermolecular interac-

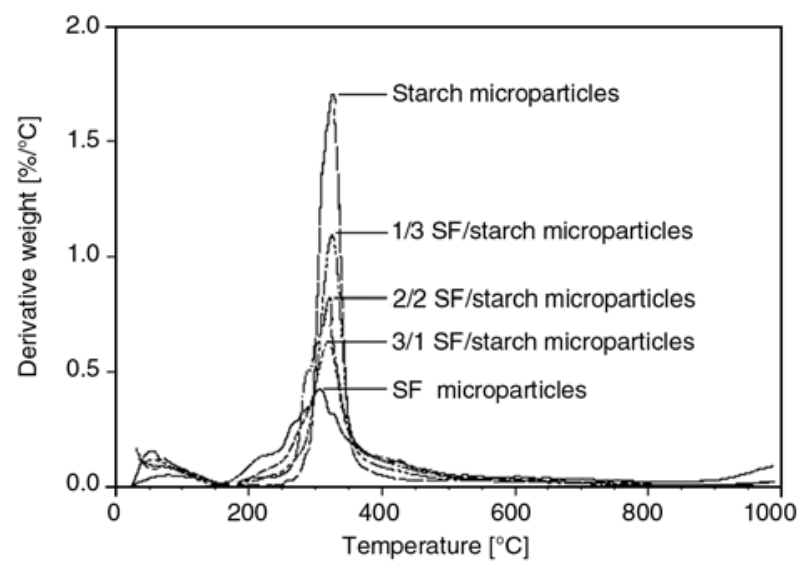

Figure 5. DTG thermograms of SF, starch and blended microparticles
Table 1. $T_{d, \max }$ of SF/starch blended microparticles

\begin{tabular}{|c|c|}
\hline SF/starch ratio (w/w) & $\mathbf{T}_{\mathbf{d}, \mathbf{m a x}}\left[{ }^{\circ} \mathbf{C}\right]$ \\
\hline $4 / 0$ & 306 \\
\hline $3 / 1$ & 319 \\
\hline $2 / 2$ & 321 \\
\hline $1 / 3$ & 325 \\
\hline $0 / 4$ & 326 \\
\hline
\end{tabular}

tions between SF and starch as according to the FTIR analysis.

\subsection{Particle sizes}

Particle size distributions of blended microparticles were measured by the sieving method instead of the scattering method (suspension in water) because of the partial swelling and dissolution of microparticles. The particle sizes are presented in Figure 6. It can be seen that both SF and starch microparticles showed the largest weight fraction in the range of $>150 \mu \mathrm{m}$ in size. This may be due to the rapid solidification of microparticle matrices during the emulsification-diffusion process which resulted in a large particle size. For the blended micropaticles, the particle sizes slightly decreased as the SF blended ratio increased. Both the $3 / 1$ and $2 / 2$ blended microparticles showed the largest weight fraction in the range of $<80 \mu \mathrm{m}$ in size. These results corresponded to their SEM images in Figure 2.

\subsection{Dissolution test}

Figure 7 shows percentage of dissolution in water of the microparticles with different incubation times. The dissolutions of all the microparticles after $3 \mathrm{hrs}$ incubation showed no differences. The $\%$ dissolution values were in range of $44-64 \%$. While for the incubation time of $6 \mathrm{hrs}$, the dissolutions of both SF and starch microparticles were nearly complete (91 and 95\%, respectively). All blended microparticles had lower \% dissolution values than those of SF and starch microparticles. The interactions between SF and starch in the blended microparticles may decrease microparticle dissolution. The 1/3 (w/w) SF/starch blended microparticles show the lowest \% dissolution. This can be explained from the FTIR analysis, the $1 / 3(\mathrm{w} / \mathrm{w})$ $\mathrm{SF} /$ starch blended microparticles contained the largest water-insoluble or $\beta$-sheet form of SF 

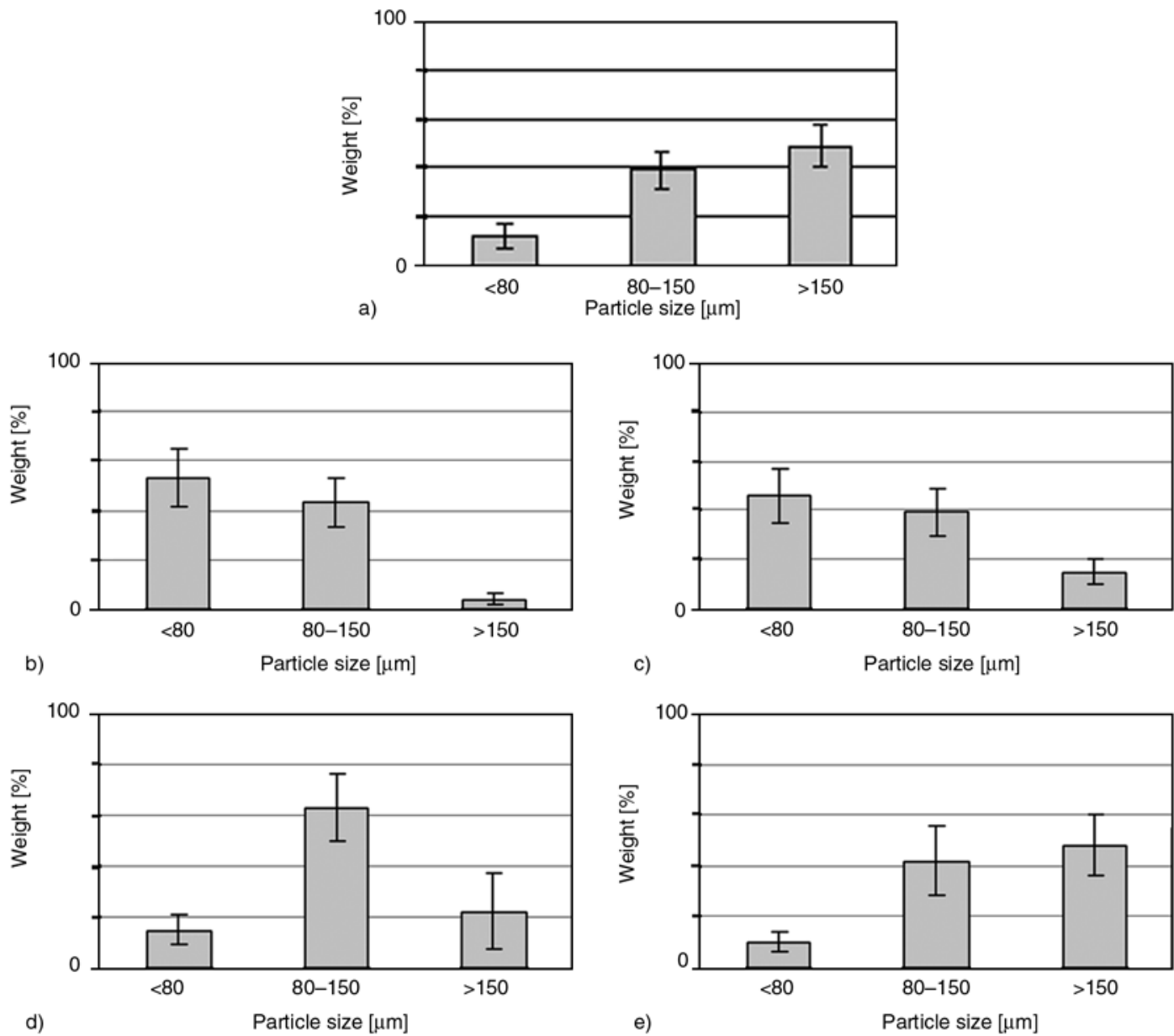

Figure 6. Particle size distributions of (a) SF, (b) 3/1 blended, (c) 2/2 blended, (d) 1/3 blended and (e) starch microparticles. Error bars are standard deviations $(n=3)$.
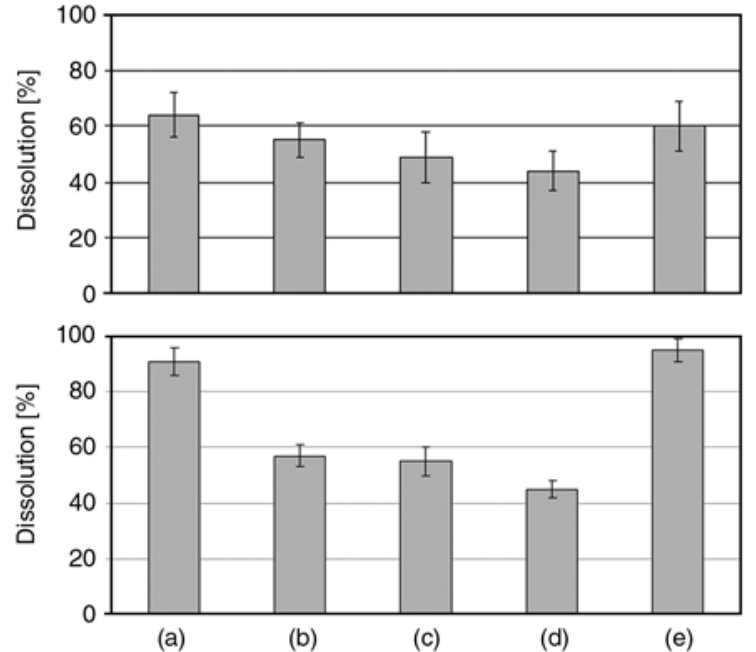

Figure 7. Dissolutions in distilled water of (a) SF, (b) 3/1 blended, (c) 2/2 blended, (d) 1/3 blended and (e) starch microparticles for incubation times of $3 \mathrm{hrs}$ (top) and 6 hrs (bottom). Error bars are standard deviations $(n=3)$.

microparticle matrices. The results suggest that the $\%$ dissolution can be controlled by adjusting the blended ratio. This is an important advantage for drug delivery application with controllable drug release rate.

\section{Conclusions}

The SF/starch blended microparticles with different blended ratios were successfully prepared by the W/O emulsion solvent diffusion method. The SF and starch solutions were firstly blended before preparing the blended microparticles. Using FTIR and TG analyses, the intermolecular interactions which exist between SF and starch molecules were determined. The SF conformation changes from random coil to $\beta$-sheet form and increasing SF thermal stability can be induced by blending with starch. The increase of starch ratios in the blended microparticles can increase interactions between $\mathrm{SF}$ and starch. Blended microparticles with a spherical shape can produce with appropriate blended ratio. The \% dissolution in water of 
blended microparticles strongly depended upon the blended ratio.

These SF/starch blended microparticles with different random coil $/ \beta$-sheet form contents, thermal stabilities and \% dissolutions might be of interested for use as controlled-release drug delivery systems.

\section{Acknowledgements}

This work was supported by the Division of Research supporting and Extension services, Mahasarakham University, fiscal year 2010 and the Center of Excellence for Innovation in Chemistry (PERCH-CIC), Commission on Higher Education, Ministry of Education, Thailand. Appreciation is also expressed to Dr. Jolyon Dodgson, Faculty of Science, Mahasarakham University for helping to improve the manuscript.

\section{References}

[1] Vepari C., Kaplan D. L.: Silk as a biomaterial. Progress in Polymer Science, 32, 991-1007 (2007). DOI: 10.1016/j.progpolymsci.2007.05.013

[2] Zhu Z. H., Ohgo K., Asukara T.: Preparation and characterization of regenerated Bombyx mori silk fibroin fiber with high strength. Express Polymer Letters, 2, 885-889 (2008).

DOI: $10.3144 /$ expresspolymlett.2008.103

[3] Kim K-H., Jeong L., Park H-N., Shin S-Y., Park WH., Lee S-C., Kim T-I., Park Y-J., Seol Y-J., Lee YM., Ku Y., Rhyu I-C., Han S-B., Chung C-P.: Biological efficacy of silk fibroin nanofiber membranes for guided bone regeneration. Journal of Biotechnology, 120, 327-339 (2005).

DOI: $10.1016 /$ j.jbiotec.2005.06.033

[4] Hofmann S., Wong Po Foo C. T., Rossetti F., Textor M., Vunjak-Novakovic G., Kaplan D. L., Merkel H. P., Meinel L.: Silk fibroin as an organic polymer for controlled drug delivery. Journal of Controlled Release, 111, 219-227 (2006).

DOI: 10.1016/j.jconrel.2005.12.009

[5] Wang X., Wenk E., Matsumoto A., Meinel L., Li C., Kaplan D. L.: Silk microspheres for encapsulation and controlled release. Journal of Controlled Release, 117, 360-370 (2007).

DOI: $10.1016 /$ j.jconrel.2006.11.021

[6] Meinel L., Hofmann S., Karageorgiou V., KirkerHead C., McCool J., Gronowicz G., Zichner L., Langer R., Vunjak-Novakovic G., Kaplan D. L.: The inflammatory responses to silk films in vitro and in vivo. Biomaterials, 26, 147-155 (2005).

DOI: $\underline{10.1016 / \text { j.biomaterials.2004.02.047 }}$
[7] Liu Y., Shao Z., Zhou P., Chen X.: Thermal and crystalline behaviour of silk fiborin/nylon 66 blend films. Polymer, 45, 7705-7710 (2004).

DOI: $10.1016 /$ j.polymer.2004.09.005

[8] She Z., Jin C., Huang Z., Zhang B., Feng Q., Xu Y.: Silk fibroin/chitosan scaffold: Preparation, characterization, and culture with HepG2 cell. Journal of Material Science: Materials in Medicine, 19, 3545-3553 (2008). DOI: 10.1007/S10856-008-3526-y

[9] Ma X. L., Li R., Ru L., Xu G. W., Huang Y. P.: Effect of polyaspartic acid on hydroxyapatite deposition in silk fibroin blend films. Express Polymer Letters, 4, 321-327 (2010).

DOI: $10.3144 /$ expresspolymlett.2010.40

[10] Yeo J-H., Lee K-G., Lee Y-W., Kim S. Y.: Simple preparation and characteristics of silk fibroin microsphere. European Polymer Journal, 39, 1195-1199 (2003).

DOI: $10.1016 / \mathrm{S} 0014-3057(02) 00359-2$

[11] Hino T., Tanimoto M., Shimabayashi S.: Change in secondary structure of silk fibroin during preparation of its microspheres by spray-drying and exposure to humid atmosphere. Journal of Colloid and Interface Science, 266, 68-73 (2003). DOI: $\underline{10.1016 / \mathrm{S} 0021-9797(03) 00584-8}$

[12] Wenk E., Wandrey A. J., Merkle H. P., Meinel L.: Silk fibroin spheres as a platform for controlled drug delivery. Journal of Controlled Release, 132, 26-34 (2008). DOI: $10.1016 / j . j$ conrel.2008.08.005

[13] Lammel A. S., Hu X., Park S-H., Kaplan D. L., Scheibel T. R.: Controlling silk fibroin particle features for drug delivery. Biomaterials, 31, 4583-4591 (2010).

DOI: $10.1016 /$ j.biomaterials.2010.02.024

[14] Deveci S. S., Basal G.: Preparation of PCM microcapsules by complex coacervation of silk fibroin and chitosan. Colloid and Polymer Science, 287, 1455-1467 (2009).

DOI: 10.1007/s00396-009-2115-z

[15] Bayram Ö. A., Bayram M., Tekin A. R.: Spray drying of sumac flavor using sodium chloride, sucrose, glucose and starch as carriers. Journal of Food Engineering, 69, 253-260 (2005).

DOI: $10.1016 /$ j.jfoodeng.2004.08.012

[16] Loksuwan J.: Characteristics of microencapsulated $\beta$ carotene formed by spray drying with modified tapioca starch, native tapioca starch and maltodextrin. Food Hydrocolloids, 21, 928-935 (2007).

DOI: 10.1016/j.foodhyd.2006.10.011

[17] Malafaya P. B., Stappers F., Reis R. L.: Starch-based microspheres produced by emulsion crosslinking with a potential media dependent responsive behavior to be used as drug delivery. Journal of Material Science: Material in Medicine, 17, 371-377 (2006). DOI: $\underline{10.1007 / \mathrm{s} 10856-006-8240-\mathrm{Z}}$ 
[18] Fang Y-Y., Wang L-J., Li D., Li B-Z., Bhandari B., Chen X. D.: Preparation of crosslinked starch microspheres and their drug loading and releasing properties. Carbohydrate Polymers, 74, 379-384 (2008). DOI: $10.1016 /$ j.carbpol.2008.03.005

[19] Elfstrand L., Eliasson A-C., Wahlgren M.: Changes in starch structure during manufacturing of starch microspheres for use in parenteral drug formulations: effects of temperature treatment. Carbohydrate Polymers, 75, 157-165 (2009).

DOI: $\underline{10.1016 / j . c a r b p o l .2008 .07 .018}$

[20] Mundargi R. C., Shelke N. B., Rokhade A. P., Patil S. A., Aminabhavi T. M.: Formulation and in-vitro evaluation of novel starch-based tableted microspheres for controlled release of ampicillin. Carbohydrate Polymers, 71, 42-53 (2008).

DOI: $10.1016 /$ j.carbpol.2007.05.013

[21] Roy A., Bajpai J., Bajpai A. K.: Dynamics of controlled release of chlorpyrifos from swelling and eroding biopolymeric microspheres of calcium alginate and starch. Carbohydrate Polymers, 76, 222-231 (2009).

DOI: $\underline{10.1016 / j . c a r b p o l .2008 .10 .013}$
[22] Kundu J., Patra C., Kundu S. C.: Design, fabrication and characterization of silk fibroin-HPMC-PEG blended films as vehicle for transmucosal delivery. Materials Science and Engineering: C, 28, 1376-1380 (2008).

DOI: 10.1016/j.msec.2008.03.004

[23] Niamsa N., Srisuwan Y., Baimark Y., Phinyocheep P., Kittipoom S.: Preparation of nanocomposite chitosan/silk fibroin blend films containing nanopore structures. Carbohydrate Polymers, 78, 60-65 (2009). DOI: 10.1016/j.carbpol.2009.04.003

[24] Klingler C., Müller B. W., Steckel H.: Insulin-microand nanoparticles for pulmonary delivery. International Journal of Pharmaceutics, 377, 173-179 (2009). DOI: 10.1016/j.ijpharm.2009.05.008

[25] Giovagnoli S., Blasi P., Schoubben A., Rossi C., Ricci M.: Preparation of large porous biodegradable microspheres by using a simple double-emulsion method for capreomycin sulfate pulmonary delivery. International Journal of Pharmaceutics, 333, 103-111 (2007). DOI: $10.1016 /$ j.ijpharm.2006.10.005

[26] Rawat A., Majumder Q. H., Ahsan F.: Inhalable large porous microspheres of low molecular weight heparin: In vitro and in vivo evaluation. Journal of Controlled Release, 128, 224-232 (2008).

DOI: $\underline{10.1016 / j . j c o n r e l .2008 .03 .013}$ 